\title{
SOCIAL AND CULTURAL CONTEXTS CHANGE BUT \\ INTELLIGENCE PERSISTS AS INCISIVE TO EXPLAIN CHILDREN'S ACADEMIC ACHIEVEMENT
}

Ana Filipa Alves (Corresponding Author)

Centro de Investigação em Educação (CIEd-FCT)/ Universidade do Minho/ Portugal/

afilipaalves@hotmail.com

Cristiano Mauro Assis Gomes

Universidade Federal de Minas Gerais/ Brasil

Ana Martins

Centro de Investigação em Educação (CIEd-FCT)/ Universidade do Minho/ Portugal

\section{Leandro da Silva Almeida}

Centro de Investigação em Educação (CIEd)/ Universidade do Minho/ Portugal

\begin{abstract}
The intelligence is a well established predictor of school achievement. Although school failure/success can be explained by cognitive variables, socio-familial variables can also have an impact. Since these variables haven't been so systematically investigated together, the present study aims to consider both variables to understand their causal roles in academic achievement. With a sample of 376 Portuguese children aged 6 to 10 years, a path analysis was carried out based on a prior analysis to search for causal relationships between intelligence and socio-familial variables to explain children's academic achievement. The results point to intelligence as a major influence on school performance, combined with socio-familial
\end{abstract}


variables (directly: community, type of school, mother's education and school year; and indirectly: socioeconomic status and father's education level). Practical implications were discussed concerning the relevance of the investigated variables in explaining academic achievement of children.

Keywords: cognitive performance, intelligence, socio-familial variables, academic achievement.

\section{Introduction}

Psychological development does not occur independently. On the contrary, it is a continuum process in a diversity of contexts that influence themselves directly and indirectly, creating a significant dynamic of stability and change in the systems (Bronfenbrenner \& Evans, 2000). The bioecological Bronfenbrenner theory assumes this position, highlighting the relevance of socio-familial variables in children's development of cognition and learning (Bronfenbrenner, 1979; Phillipson, 2010; Pomerantz \& Dong, 2006; Wentzel, Battle, Russell, \& Looney, 2010; You \& Sharkey, 2009). Bronfenbrenner (1979) identifies five interconnected levels of influence - microsystem, mesosystem, exosystem, macrosystem, and chronosystem. The immediate quotidian is the microsystem, and the interaction between the several microsystems where the child is inserted (relationships and dynamics existing in the family routine, school and peer group, with particular attention to school, extracurricular and children's leisure activities) is the mesosystem. The exosystem assumes the connection between two or more contexts and the macrosystem is identified with cultural, political and economic realities. The chronosystem corresponds to the temporal dimension and covers the various systems in which the child develops, shaping opportunities for development and learning, paying particular attention to 
life transitions or the socio-historical circumstances (Collins, Maccoby, Steinberg, Heatherington, \& Bornstein, 2000; Tudge, Mokrova, Hatfield, \& Karnik, 2009).

In this way, the cognitive development of each child may be more or less enhanced, highlighted and valued, depending on the interaction with its closest contexts and the existing exogenous conditions that shape these interactions. Childhood is assumed as a period in which the body is more sensitive to environmental influences, finding itself in constant interaction with the surrounding environment. The resulting interactions are associated with a continuous evolution that takes place at various levels, namely the affective, cognitive and social. Nevertheless, beyond the intrapersonal characteristics of the child, the family and the school environment, which are immediate systems, are the contexts that influence the developmental pathways of children more systematically (Johnson, 2010; Phillipson, 2010; Pomerantz \& Dong, 2006), especially during the preschool and school years.

During childhood, parents transmit different experiences and enhance interactions that favor formal and informal knowledge development, like early literacy, vocabulary and numeracy, which assume relevant role in initial school learning (Campos, Almeida, Ferreira, Martinez, \& Ramalho, 2013; Torppa, Poikkeus, Laakso, Eklund, \& Lyytinen, 2006; Vidmar, Niklas, Schneider, \& Schneider, 2016). These daily interactions influence the development of language and thinking competencies, as well as the development of several basic cognitive skills required for school learning. Acquired informal experience provides different ways to learn, operate and acquire formal experience, having an impact on school-based learning. This is why the connection between the family and school contexts is essential for successful educational achievement (Galindo \& Sheldon, 2012; García \& Rosel, 2001; Jeynes, 2005).

Apart from the traditional relationship between intelligence and academic achievement (Chamorro-Premuzic \& Arteche, 2008; Deary, Strand, Smith, \& Fernandes, 2007; Laidra, 
Pillmann, \& Allik, 2007; Lemos, Abad, Almeida, \& Colom, 2014; Primi, Ferrão, \& Almeida, 2010; Strenze, 2007), several studies recognize the existence of the influence of socio-familial variables on children's cognitive and academic performance (Freijo et al., 2008; Lugo-Gil \& Tamis-LeMonda, 2008; Von Stumm, Macintyre, Batty, Clark, \& Deary, 2010). These variables configure different family profiles that will affect/model the learning process of children. In this sense, full explanations of cognitive development involving cognitive functions seem to be scarce. Indeed, research shows a systematic decreasing in academic achievement by children's from family with lowers socioeconomic and educational levels (Cabrera, Shannon, \& TamisLeMonda, 2007; Cianci, Orsini, Hulbert, \& Pezzuti, 2013; Davis-Kean, 2005; Hill et al., 2004; Rindermann, Michou, \& Thompson, 2011; Strenze, 2007).

However, lower levels of school success are also a reality among children from disadvantaged economic and academic backgrounds, so it is important to understand the relationship between these children and parents. In fact, the nature and extent of parental involvement/availability in education and the learning of children, as well as the quality of support with homework, influence the cognitive development of children and constitute important factors in differentiating patterns of cognitive and academic realization (Davis-Kean, 2005; Galindo \& Sheldon, 2012; Jeynes, 2005; Rothon, Arephin, Klineberg, Cattell, \& Stansfeld, 2011; Stull, 2013; Zhan, 2006).

Taking into account the importance of personal and family variables in the academic performance of children, this study aims to verify the causal role of intelligence and sociofamilial variables. After several and incisive cultural and social changes, also in educational contexts, this article introduce a large number of socio-familiar variables allowing to identify which ones actually have an impact in children's academic achievement. This way, we intend to explore the impact of variables instead of test the existing models. 


\section{Method}

\subsection{Participants}

In Portugal, compulsory education is organized into three levels (1st, 2nd and 3rd) of basic education, with nine grades, and a secondary education level having three grades.

This study considered children in the 1st cycle of basic education, which concerns a 4-year basic education. A total of 376 Portuguese children evenly distributed by gender (47.9\% boys and 52.1\% girls), aged between 6 and 10 years old $(M=7.50, S D=1.21)$, living in rural (50.3\%) and urban (49.7\%) areas in the northern and central regions of the country, attending public (63.6\%) and private (36.4\%) schools participated in this study. Children identified with special educational needs and having repeated grade retention in school were not considered in the study.

\subsection{Measures}

The Cognitive Competencies Scale from 4 to 10 years old - ECCOs $4 / 10$ - is a cognitive assessment battery applied individually, created for the Portuguese population (Brito \& Almeida, 2009). ECCOs 4/10 organizes subtests into a sequence of six cognitive operations that assess the perception (codification and perceptual attention to details), short-term memory (attention, retention and immediate recall of digits), understanding (grasping elements and senses in a context), reasoning (grasping and applying relationships between elements), problem-solving (performing tasks guided by a broader scope of information to be processed) and divergent thinking (production of ideas, originality and fluency) (Brito \& Almeida, 2009). These six processes are evaluated through tasks using two types of content: one connected to verbal tasks, while the other is more figurative, manipulative and practical. From the 
combination of processes and content result eleven subtests that compose this battery: Elements in Phrases, Absurd Phrases, Verbal Analogies, Quantitative Tasks, Construction of Stories, Comparison of Pictures, Elements on Trees, Absurd Drawings, Analogy of Figures, Pattern Composition and Construction of Figures. In addition to the verbal and non-verbal scores, we arrived at a global intelligence quotient, which is the value used in our study. This intelligence composite measure is made of tasks that are related to the daily activities of children, using playful and colorful materials. The results obtained with this scale show high internal consistency indices, between 0.87 and 0.97 . Validity studies show a significant and positive correlation between ECCOs and WPPSI or WISC scores (Brito \& Almeida, 2009; Brito, Almeida, Ferreira, \& Guisande, 2011).

Personal and socio-familial variables (sex, age, school grade, time (more or less than an hour per day) and type of task with parents (school activities or free time activities), number of siblings, place in the phratry, socioeconomic status (low, medium and high), type of school (private or public), community (urban or rural), parental educational level) information were obtained from the children, parents and teachers.

The information about students' academic achievement was collected from their teachers, and an overall grade was calculated (average grade).

\subsection{Procedures}

In order to fulfill ethical requirements, authorization applications to the ethics committee of the University and to the Ministry of Education were made and received approval. After approval, those were addressed to school directors and parents, accompanied by the explanation of the nature of the research and its objectives. Students were also informed of the study's objectives and the tasks to be performed. Anonymity and confidentiality of the collected data were assured, 
as well as the voluntary nature of participation. The battery of tests was applied individually in two sessions during class hours as allowed by teachers, which required around 90 minutes. The instructions in the manual were strictly followed.

\subsection{Statistical procedure}

Some algorithms of the TETRAD software version $\mathrm{V}$ are used in this study, aiming to find causal structures from the data. The algorithms applied are the causal search Peter-Clark (PC), the Greedy Equivalency Search (GES), and the Linear Non-Gaussian Acyclic Models (LiNGAM). Technical details of these algorithms are shown in TETRAD' manual (Glymour, Scheines, Spirtes, \& Ramsey, 2015). These three algorithms assume an acyclic causal structure in the data, and presuppose that the structure has a linear property and data is independent. All the solutions from the TETRAD algorithms produce a chi-square value, the degrees of freedom of the solution, as well as the p-value of the chi-square/degrees of freedom ratio and the Bayesian Information Criterion (BIC). This latter is used to compare the solutions, where the lowest value indicates the best model.

The solutions obtained by each of the TETRAD algorithms were tested through the use of the path analysis confirmatory approach, applying the maximum likelihood (ML) approach, using MPlus software (version 7.11) (Muthen \& Muthen, 1998-2014).

The global adjustment of the model was assessed using the following indices: the Comparative Fit Index (CFI; Bentler, 1990) and the Tucker-Lewis index (TLI; Bentler \& Bonnet, 1980) with a cutoff value of equal to or greater than .95; the root mean square error of approximation (RMSEA; Steiger et al., 1985) with a cutoff value of equal to or less than .06; and the standardized root mean square residual (SRMR; Hu \& Bentler, 1999) with a cutoff value of equal to or less than .08 (Marôco, 2014; Schumacker \& Lomax, 2004). Degrees of freedom and 
$\chi^{2}$ are also reported. To compare the models we considered the adjustment indices BIC, BIC adjusted, AIC, CFI and RMSEA. For one model to be considered better than another, the RMSEA difference has to be less than .015 (favoring the lower value), the CFI difference has to be greater than .01 (favoring the higher value) and the difference in the BIC (Chen, 2007; Cheung \& Rensvold, 2002), BIC adjusted or AIC has to be greater than 6 points (favouring the lower value) (Kass \& Raftery, 1995).

It should also be noted that the percentages presented in the obtained results are calculated considering the load value squared and then multiplied by 100 .

\section{Results}

The solution from the GES algorithm presents $\chi^{2}[298]=450.55, p<.001$, for the chisquares/degrees of freedom ratio and $\mathrm{BIC}=-1316.47$. The PC algorithm shows

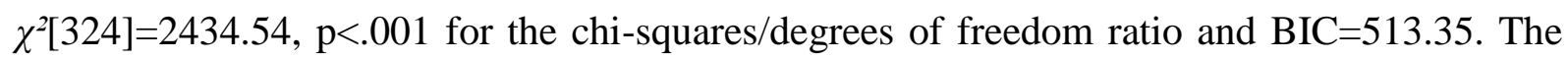
LiNGAM algorithm did not converge (Table 1). The two solutions that converged were run again through path analysis, respecting all the causal or covariance relationships indicated by them. The PC algorithm model presents a chi-square of 1363.85 and 324 degrees of freedom, and a p-value of 0.000 . This model is unacceptable because its data fit possesses a CFI equal to .81 and a TLI equal to .82. The minimum for CFI and TLI values is 0.95. Beyond that, the RMSEA presents a value of .09 and values equal to or over .10 are unacceptable. The unique index that shows a good data fit is SRMR (.06) (Table 1). So, the PC model does not possess the minimum data fit and cannot represent the causal structure of the data. The GES algorithm model shows a chi-square of 338.33 and 298 degrees of freedom, and a p-value of 0.05 . All the data fit indexes present very good data fit: CFI and TLI=.99, SRMR=.04 and RMSEA $=.02$, with 90\% confidence interval of .000 and .028 (Table 1). 
It is possible to say that the GES solution is better than the PC solution, because the difference (BIC GES - BIC PC = -1829.82) in the BIC index (Table 1) of these two models is relevant and sufficient for deciding in favor of one solution to the detriment of the other (Kass \& Raftery, 1995). So, the GES model is a viable model according to all data fit indexes.

Table 1

Solutions from the TETRAD Algorithms and Fit Indices of Path Analysis.

\begin{tabular}{l|cccc|cccccc} 
& \multicolumn{4}{|c|}{ Solutions from the TETRAD } & \multicolumn{5}{c}{ Fit Indices of Path Analysis } \\
\hline Algorithms & Df & $\chi^{2}$ & $p$ & BIC & Df & $\chi^{2}$ & CFI & TLI & RMSEA & SRMR \\
\hline GES & 298 & 450.55 & $<.001$ & -1316.47 & 298 & 338.33 & .99 & .99 & .02 & .04 \\
\hline PC & 324 & 2434.54 & $<.001$ & 513.35 & 324 & 1363.85 & .81 & .82 & .09 & .06 \\
\hline LINGAM & \multicolumn{4}{|c|}{ not converged } \\
\hline
\end{tabular}

The solutions of the algorithms that converged (GES and PC) differ widely. The GES solution provides information that school performance (SP) is directly caused by five variables: intelligence quotient (IQ, 21.38\%, $\mathrm{p}<.001$ ); community (C - urban/rural, 14.46\%, $\mathrm{p}<.001$ ); type of school (TS - public/private, 11.79\%, p<.001); mother's educational level (MEL, 2.81\% $(\mathrm{p}<.01)$; and school grade (SG, 1.91\%, $\mathrm{p}<.01)$ (in the later grades, lower academic performance is seen.) As we can see, (Figure 1) only intelligence quotient, community and type of school show moderate loadings (Cohen, 1988) on school performance.

We also report the variables that indirectly cause school performance (SP), when loading is at least .30. The educational level of the father (FEL) indirectly causes school performance (SP), because the former directly causes IQ $(10.11 \%, \mathrm{p}<.001)$, which causes SP. Socio-economic status (SES) and community (C) influence FEL (32.73\% and 6.91\%, $<<.001$, respectively) and SES influences mother's educational level (MEL, 10.60\%, $\mathrm{p}<.001)$. The SES also influences the type of school (TS) that the children attend (49.27\%, $\mathrm{p}<.001)$. 


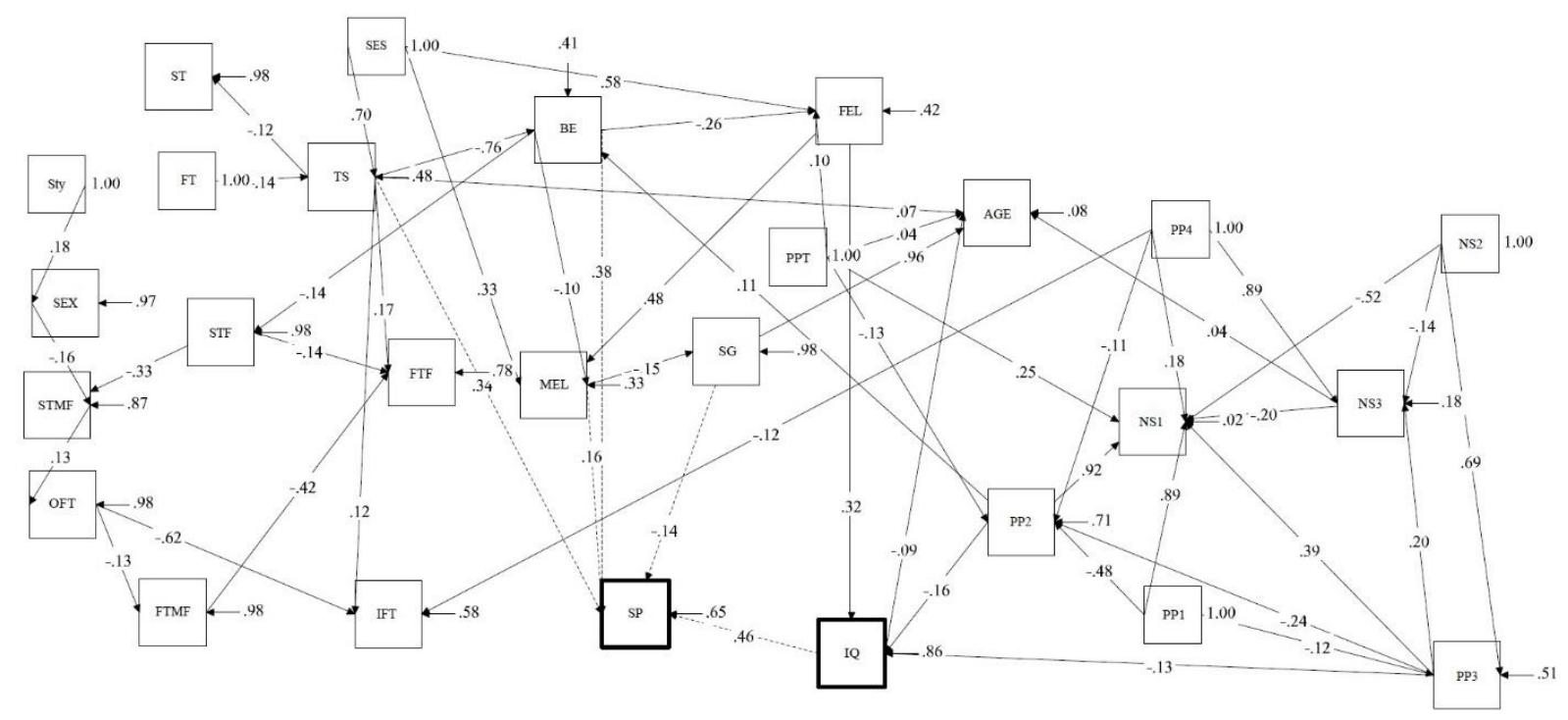

Figure 1. GES model revised.

Note. IQ = intelligence quotient; NS1 = one sibling; NS2 = two siblings; NS3 = three siblings; PP1 = first place in the phratry; PP2 = second place in the phratry; PP3 = third place in the phratry; PP4 = fourth place in the phratry; PPT = twins; SES = socioeconomic status; $\mathrm{TS}=$ type of school; $\mathrm{C}=$ community; $\mathrm{MEL}=$ mother's educational level; FEL = father's educational level; SP = school performance; Sty = study; ST = school tasks more than 1hour/day; FT = free time more than 1hour/day; STF = school tasks with father; STMF = school tasks with mother and father; IFT = inside free time; OFT = outside free time; FTF = free time with father; FTMF = free time with mother and father; SG = school grade; - - - - - - direct influence on SP.

The PC solution (Figure 2) provides information that only one variable influences school performance (SP) directly, mother's educational level (MEL, 10.18\%, p<.001), with a higher percentage than in the previous algorithm. Socio-economic status (SES), as with the GES algorithm, influences the educational level of the mother (MEL) and father (FEL) and the type of school (TS) attended by the children (12.92\%, 47.76\%, 49.27\%, $\mathrm{p}<.001$, respectively). With this algorithm, the percentage related to the influence of parents' educational levels increases and the percentage related to the type of school remains stable (Figure 2). 


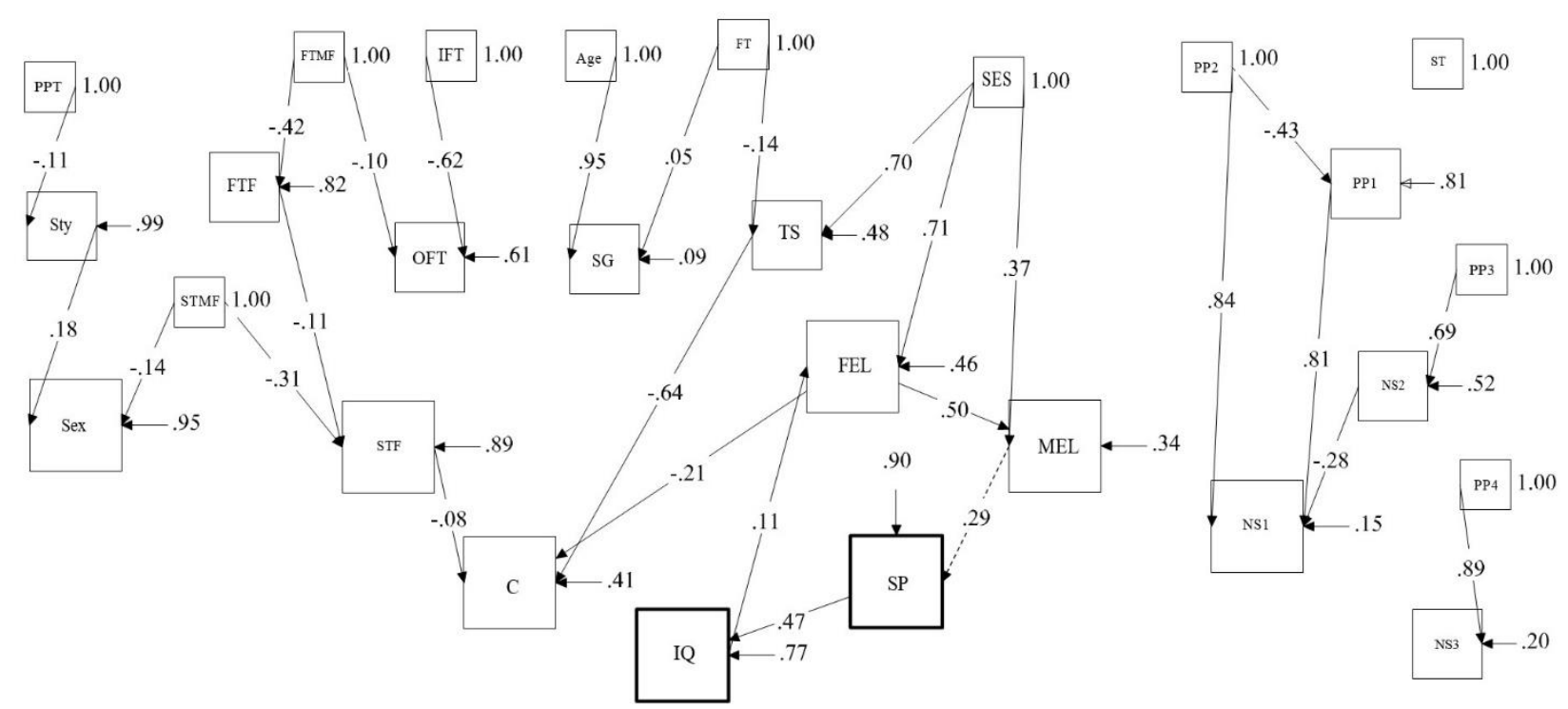

Figure 2. PC model

Note. IQ = intelligence quotient; NS1 = one sibling; NS2 = two siblings; NS3 = three siblings; PP1 = first place in the phratry; PP2 = second place in the phratry; PP3 = third place in the phratry; PP4 = fourth place in the phratry; PPT = twins; SES = socioeconomic status; TS = type of school; $\mathrm{C}=$ community; MEL = mother's educational level; FEL = father's educational level; SP = school performance; Sty = study; ST = school tasks more than 1hour/day; FT = free time more than 1hour/day; STF = school tasks with father; STMF = school tasks with mother and father; IFT = inside free time; OFT = outside free time; FTF = free time with father; FTMF = free time with mother and father; SG = school grade; - - - - - - direct influence on SP.

Despite the good data fit in the GES model, it is important to verify the existence of falsepositives, that is, causal relationships determined by the algorithms that are in fact correlations between variables. Thus, we have taken as our starting point the GES model and investigated the false positives of this model because it was the best model. We inverted the causal connections between the variables of this model, one by one. However, given the high number of variables, for this procedure we only consider the variables explored previously when loading is at least .30. Beyond that, we also changed the causal connections of every pair of variables, thus turning them into correlations. If either of the new models (inversion or correlation) showed a better data fit than the reference model, the latter must be changed, becoming in this a new reference model for subsequent models. In this way, the original model would not serve 
more as the comparative model to be used with the next substitutions, and so on. We have used BIC, BIC adjusted, AIC, CFI and RMSEA to compare the reference model and the substitutions created. We consider a substitution to have shown a same data fit as the comparative model if the RMSEA difference between them was less than .015, or the CFI difference was greater than .01 , or the difference between BIC, BIC adjusted or AIC were less than 6. Table 2 shows in detail inversion and correlation examples, as well as their data fit and their differences in relation to the reference model. In order to better understand the issue, we analyze the following example: we verify that reversing the influence of the school year and academic performance or correlating both variables did not improve the model fit (Table 2). It should be noted that the models that were compared to the reference model were those related to school performance, because this variable occupied the most important role in the causal structure of the model. Figure 1 shows the GES model revised through the strategy to find and correct the false positives in causation. We should observe that this model is similar to the original GES model.

Table 2

Data Fit of the Original GES model and all the causal and correlational substitutions

\begin{tabular}{lccccccc}
\hline substitutions & $\chi^{2}$ & df & BIC & BIC adj & AIC & CFI & RMSEA \\
\hline GES original & 338.33 & 298 & 10757,400 & 10417,916 & 10336,934 & 0,992 & 0,019 \\
IQ ON SP & 357.833 & 298 & 10776.898 & 10437.414 & 10356.432 & 0.989 & 0.023 \\
difference & & & 19.498 & 19.498 & 19.498 & -0.003 & 0.004 \\
SP WITH IQ & & & 10762.985 & 10423.500 & 10342.519 & 0.991 & 0.020 \\
difference & & & 5.585 & 5.584 & 5.585 & $-0,001$ & 0,001 \\
SG ON SP & 345,531 & 298 & 10764,596 & 10425,112 & 10344,13 & 0,991 & 0,021 \\
difference & & & 7,196 & 7,196 & 7,196 & $-0,001$ & 0,002 \\
SG WITH SP & 338,33 & 298 & 10757,400 & 10417,916 & 10336,934 & 0,992 & 0,019 \\
difference & \multicolumn{7}{c}{0} \\
Note. IQ = intelligence quotient; SP = school performance; SG = school grade
\end{tabular}




\section{Discussion and Conclusion}

Although academic success/failure can be explained by cognitive variables, it does not imply that learning and school performance are only explained by the personal factors of students, particularly those associated with intellectual capacity (Chamorro-Premuzic \& Arteche, 2008; Deary et al., 2007; Lemos et al., 2014). Thus, this study encompasses a wide range of variables that in other investigations are analyzed separately (sex, age, school grade, time and type of task with parents, number of siblings, place in the phratry, socioeconomic status, type of school, community, parental educational level, cognitive development and school performance), with robust methodologies, including techniques of causal relationships that allow defining causal paths.

As we can see, only a few variables have been shown to have a predictive value in the academic performance of children, which is already an important feature. Here, we only discuss the variables that showed implications for academic achievement (directly or indirectly). As first conclusion, the intelligence quotient obtained by the children in the cognitive performance test was the variable with the highest percentage of direct impact on academic performance. In this regard, research has shown statistically significant positive correlations between intelligence tests and school results (Deary et al., 2007; Farsides \& Woodfield, 2003; Naglieri \& Bornstein, 2003; Sternberg, Grigorenko, \& Bundy, 2001; Strenze, 2007). In our study, more than a mere correlation, we highlight a causal relationship, where the intelligence quotient has a decisive role in the school performance of children.

With less influence but still with moderate and statistically significant values, corroborating findings in the literature (Alves, Lemos, Brito, Martins, \& Almeida, in press; Strenze, 2007), the community (urban/rural) and the type of school (public/private) converge in the same direction; that is, they have impact on academic performance. We cannot also neglect the 
indirect influence of socioeconomic status on school type and this, in turn, on academic success. Children from families with higher socio-economic levels have better cognitive performance (Bradley \& Corwyn 2002; Cabrera et al., 2007; Guo \& Harris, 2000; Lemos, Almeida, \& Colom, 2011; Strenze, 2007), by possessing the possibility of greater access to material and human resources, and entertainment and educational contexts, as well as the possibility to attend schools with different educational facilities, more stimulating and more capacitated infrastructures.

On the one hand the mother's educational level has a direct impact on children's academic performance (very low, but statistically significant); on the other hand, the educational level of the father has a direct impact on cognitive performance and this, in turn, affects school performance. As can be seen in the causal relationships obtained, mothers have greater impact in school achievement, perhaps because mothers traditionally assume greater monitoring of the child's learning tasks (Alves et al., in press). Thus, their academic levels turn out to be reflected in the results obtained by their children. As for father's educational level, it introduced itself as a better cognitive performance predictor (Mullis, Rathge, \& Mullis, 2003) compared to the educational level of the mother, contrary to some reports in the area (Alves et al., in press; Gutman, Sameroff, \& Cole, 2003).

In terms of general conclusion, this study reinforces the traditional influence of IQ on children's academic success nowadays, but academic achievement variance can be better explained if IQ and socio-familial variables are combined. So, the results corroborate the relevance of sociofamilial variables and direct and indirect effects on cognitive development, learning, and school success/failure of children (Sánchez et al., 2013; Phillipson, 2010; Wentzel, Battle, Russell, \& Looney, 2010; You \& Sharkey, 2009). In practice, these results reinforce the importance of a holistic evaluation. That is, for a cognitive performance evaluation and a systemic psychosocial 
intervention to understand the obtained school results, one must consider the impact of sociofamilial variables (Lee \& Shute, 2010). The family variables are also important in psychosocial intervention to promote children's cognitive development and school learning.

A few improvements may be undertaken in future research: including other personal, family and school variables (i.e., curriculum and teaching); considering other academic performance indicators; and qualifying parents' educational practices (i.e., time spent and type of tasks performed with children).

\section{Conflict of interest}

The authors of this article declare no conflict of interest.

\section{Acknowledgements}

The author(s) disclosed receipt of the following financial support for the research, authorship, and/or publication of this article: This work was supported by the Fundação para a Ciência e Tecnologia, IP (FCT) and the POCH/FSE under Grant SFRH/BD/85110/2012 to Ana Filipa Alves.

\section{References}

Alves, A. F., Lemos, G. C., Brito, L., Martins, A. A., \& Almeida, L. S. (in press). Desempenho cognitivo na infância: A mãe e o meio urbano fazem a diferença. Psicologia: Teoria e Pesquisa, 32(2).

Bradley, R., \& Corwyn, R. (2002). Socioeconomic status and child development. Annual Review of Psychology, 53, 371-399. http://dx.doi.org/10.1146/annurev.psych.53.100901.135233

Brito, L., \& Almeida, L. S. (2009). Escala de Competências Cognitivas para Crianças - ECCOs 4/10: Manual. Porto: Edição dos autores. 
Brito, L., Almeida, L., Ferreira, A. I., \& Guisande, M. A. (2011) Contribución de los procesos y contenidos a la diferenciación cognitiva en la infancia: Un estudio con escolares portugueses. Infancia y Aprendizaje, 34(3), 323-336. http://dx.doi.org/10.1174/021037011797238540

Bronfenbrenner, U. (1979). The ecology of human development: Experiments by nature and design. Cambridge: Harvard University Press.

Bronfenbrenner, U., \& Evans, G. W. (2000). Developmental Science in the 21st Century: Emerging Questions, Theoretical Models, Research Designs and Empirical Findings. Social Development, 9(1), 115-125. http://dx.doi.org/10.1111/1467-9507.00114

Cabrera, N., Shannon, J., \& Tamis-LeMonda, C. (2007). Fathers' influence on their children's cognitive and emotional development: From toddlers to pre-k. Applied Development Science, 11(4), 208-213. http://dx.doi.org/10.1080/10888690701762100

Campos, I. S., Almeida, L. S., Ferreira, A. I., Martinez, L. F., \& Ramalho, G. (2013). Cognitive processes and math performance: A study with children at third grade of basic education. European Journal of Psychology of Education, 28(2), 421-436. http://dx.doi.org/10.1007/s10212-012-0121-x

Chamorro-Premuzic, T., \& Arteche, A. (2008). Intellectual competence and academic performance: Preliminary validation of a model. Intelligence, 36, 564-573. http://dx.doi.org/10.1016/j.intell.2008.01.001

Chen, F.F. (2007). Sensitivity of goodness of fit indices to lack of measurement invariance. Structural Equation Modeling, 14, 464-504. http://dx.doi.org/10.1080/10705510701301834

Cheung, G.W. \& Rensvold, R.B. (2002). Evaluating goodness-of-fit indexes for testing measurement invariance. Structural Equation Modeling, 9, 233-255. http://dx.doi.org/10.1207/S15328007SEM0902_5

Cianci, L., Orsini, A., Hulbert, S., \& Pezzuti, L. (2013). The influence of parents' education in the Italian standardization sample of the WISC-III. Learning and Individual Differences, 28, 47-53. http://dx.doi.org/10.1016/j.lindif.2013.09.009

Cohen, J. (1988). Statistical power analysis for the behavioral sciences ( $2^{\text {nd }}$ ed.). Hillsdale, NJ: Lawrence Erlbaum Associates.

Collins, W. A., Maccoby, E. E., Steinberg, L., Heatherington, E. M., \& Bornstein, M. H. (2000). Contemporary research on parenting: The case for nature and nurture. American Psychologist, 55(2), 218-232. http://dx.doi.org/10.1037/0003-066X.55.2.218 
Davis-Kean, P. (2005). The influence of parent education and family income on child achievement: The indirect role of parental expectations and the home environment. Journal of Family Psychology, 19(2), 294304. http://dx.doi.org/10.1037/0893-3200.19.2.294

Deary, I. J., Strand, S., Smith, P., \& Fernandes, C. (2007). Intelligence and educational achievement. Intelligence, 35, 13-21. http://dx.doi.org/10.1016/j.intell.2006.02.001

Farsides, T., \& Woodfield, R. (2003). Individual differences and undergraduate academic success: The roles of personality, intelligence, and application. Personality and Individual Differences, 34(7), 1225-1243. http://dx.doi.org/10.1016/S0191-8869(02)00111-3

Freijo, E., Oliva, A., Olabarrieta, F., Martín, J., Manzano, A., \& Richards, M. (2008). Quality of family context or sibling status? Influences on cognitive development. Early Child Development and Care, 178, 153164. http://dx.doi.org/10.1080/03004430600685373

Galindo, C., \& Sheldon, S. (2012). School and home connections and children's kindergarten achievement: The mediating effects of family involvement. Early Childhood Research Quarterly, 27(1), 90-103. http://dx.doi.org/10.1016/j.ecresq.2011.05.004

García, F. J., \& Rosel, J. (2001). Family and personal correlates of academic achievement. Psychological Reports, 88, 533-547. http://dx.doi.org/10.2466/pr0.2001.88.2.533

Glymour, C., Scheines, R., Spirtes, P., \& Ramsey, J. (2015). TETRAD version V: Manual. Retrieved in 2015 from http://www.phil.cmu.edu/projects/tetrad/new_manual.pdf

Guo, G., \& Harris, K. M. (2000). The mechanisms mediating the effects of poverty on children's intellectual development. Demography, 37, 431-447. http://dx.doi.org/10.1353/dem.2000.0005

Gutman, L. M., Sameroff, A. J., \& Cole, R. (2003). Academic growth curve trajectories from the 1st grade to 12st grade: Effects of multiple social risk factors and preschool child factors. Development Psychology, 39(4), 777-790. http://dx.doi.org/10.1037/0012-1649.39.4.777

Hill, N. E., Castellino, D. R., Lansford, J. E., Nowlin, P., Dodge, K. A., Bates, J. E., \& Pettit, G. S. (2004). Parent academic involvement as related to school behavior, achievement and aspirations: Demographic variations across adolescence. Child Development, 75(5), 1491-1509. http://dx.doi.org/10.1111/j.1467-8624.2004.00753.x 
Jeynes, W. (2005). A meta-analysis of the relation of parental involvement to urban elementary school student $\begin{array}{llll}\text { academic } & \text { achievement. } & \text { Urban }\end{array}$ http://dx.doi.org/10.1177/0042085905274540

Johnson, W. (2010). Understanding the genetics of intelligence: Can height help? Can corn oil? Current Directions in Psychological Science, 19(3), 177-182. http://dx.doi.org/10.1177/0963721410370136

Kass, R. E., \& Raftery, A. E. (1995). Bayes factors. Journal of the American Statistical Association, 90(430), 773795. http://dx.doi.org/10.1080/01621459.1995.10476572

Laidra, K., Pillmann, H., \& Allik, J. (2007). Personality and intelligence as predictors of academic achievement: A cross-sectional study from elementary to secondary school. Personality and Individual Differences, 42, 441-451. http://dx.doi.org/10.1016/j.paid.2006.08.001

Lee, J., \& Shute, V. J. (2010). Personal and social-contextual factors in K-12 academic performance: An integrative perspective on student learning. Educational Psychologist, 45(3), 185-202. http://dx.doi.org/10.1080/00461520.2010.493471

Lemos, G. C., Abad, F. J., Almeida, L. S., \& Colom, R. (2014). Past and future academic experiences are related with present scholastic achievement when intelligence is controlled. Learning and Individual Differences, 32, 148-155. http://dx.doi.org/10.1016/j.lindif.2014.01.004

Lemos, G. C., Almeida, L., \& Colom, R. (2011). Intelligence of adolescents is related to their parents' educational level but not to family income. Personality and Individual Differences, 50(7), 1062-1067. http://dx.doi.org/10.1016/j.paid.2011.01.025

Lugo-Gil, J., \& Tamis-LeMonda, C. (2008). Family Resources and Parenting Quality: Links to Children’s Cognitive Development Across the First 3 Years. Child Development, 79(4), 1065-1085. http://dx.doi.org/10.1111/j.1467-8624.2008.01176.x

Marôco, J. (2014) Análise estatística com utilização do SPSS (6ª ed.). Pêro Pinheiro: ReportNumber.

Mullis, R. L., Rathge, R., \& Mullis, A. K. (2003). Predictors of academic performance during early adolescence: A contextual view. International Journal of Behavioral Development, 27, 541-548. http://dx.doi.org/10.1080/01650250344000172

Muthen, L. K., \& Muthen, B. O. (1998-2014). MPlus user's guide (7th ed.). Los Angeles, CA: Muthen \& Muthen. Naglieri, J. A., \& Bornstein, B. T. (2003). Intelligence and achievement: Just how correlated are they? Journal of Psychoeducational Assessment, 21, 244-260. http://dx.doi.org/10.1177/073428290302100302 
Phillipson, S. N. (2010). Modeling parental role in academic achievement: Comparing high-ability to low- and average-ability students. Talent Development \& Excellence, 2, 83-103. ISSN: 1869-2885

Pomerantz, E. M., \& Dong, W. (2006). Effects of mothers' perceptions of children's competence: The moderating role of mother's theories of competence. Developmental Psychology, 42, 950-961. http://dx.doi.org/10.1037/0012-1649.42.5.950

Primi, R., Ferrão, M. E., \& Almeida, L. S. (2010). Fluid intelligence as a predictor of learning: A longitudinal multilevel approach applied to math. Learning and Individual Differences, 20, 446-451. http://dx.doi.org/10.1016/j.lindif.2010.05.001

Rindermann, H., Michou, C. D., \& Thompson, J. (2011). Children's writing ability: Effects of parent's education, mental speed and intelligence. Learning and Individual Differences, 21, 562-568. http://dx.doi.org/10.1016/j.lindif.2011.07.010

Rothon, C., Arephin, M., Klineberg, E., Cattell, V., \& Stansfeld, S. (2011). Structural and socio-psychological influences on adolescents' educational aspirations and subsequent academic achievement. Social Psychology of Education, 14(2), 209-231. http://dx.doi.org/10.1007/s11218-010-9140-0

Schumacker, R. E., \& Lomax, R. G. (2004). A beginner's guide to structural equation modeling. London: Lawrence Erlbaum Associates.

Sternberg, R., Grigorenko, E., \& Bundy, D. (2001). The predictive value of IQ. Merrill-Palmer Quarterly, 47(1), 1-4. http://dx.doi.org/10.1353/mpq.2001.0005

Strenze, T. (2007). Intelligence and socioeconomic success: A meta-analytic review of longitudinal research. Intelligence, 35, 401-426. http://dx.doi.org/10.1016/j.intell.2006.09.004

Stull, J. C. (2013). Family socioeconomic status, parent expectations, and a child's achievement. Research in Education, 90, 53-67. http://dx.doi.org/10.7227/RIE.90.1.4

Torppa, M., Poikkeus, A.-M., Laakso, M.-L., Eklund, K., \& Lyytinen, H. (2006). Predicting delayed letter knowledge development and its relation to grade 1 reading achievement among children with and without familial risk for dyslexia. Developmental Psychology, 42(6), 11281142. http://dx.doi.org/10.1037/0012-1649.42.6.1128

Tudge, J. R., Mokrova, I., Hatfield, B. E., \& Karnik, R. (2009). Uses and misuses of Bronfenbrenner's bioecological theory of human development. Journal of Family Theory \& Review, 1, 198-210. http://dx.doi.org/10.1111/j.1756-2589.2009.00026.x 
Vidmar, M., Niklas, F., Schneider, W., \& Hasselhorn, M. (2016)..On-entry assessment of school competencies and academic achievement: a comparison between Slovenia and Germany. European Journal of Psychology of Education. http://dx.doi.org/10.1007/s10212-016-0294-9

Von Stumm, S., Macintyre, S., Batty, D. G., Clark, H., \& Deary, I. J. (2010). Intelligence, social class of origin, childhood behavior disturbance and education as predictors of status attainment in midlife: The Aberdeen Children of the 1950s study. Intelligence, 38, 202-211. http://dx.doi.org/10.1016/j.intell.2009.11.004

Wentzel, K. R., Battle, A., Russell, S., \& Looney, L. (2010). Social supports from teachers and peers as predictors of academic and social motivation. Contemporary Educational Psychology, 35, 193-202. http://dx.doi.org/10.1016/j.cedpsych.2010.03.002

You, S., \& Sharkey, J. (2009). Testing a development-ecological model of student engagement: A multilevel latent growth curve analysis. Educational Psychology, 29, 659-684. http://dx.doi.org/10.1080/01443410903206815

Zhan, M. (2006). Assets, parental expectations and involvement, and children's educational performance. Children and Youth Services Review, 28, 961-975. http://dx.doi.org/10.1016/j.childyouth.2005.10.008 